\title{
CALCITONIN GENE-RELATED PEPTIDE-IMMUNOREACTIVE NERVES IN CARCINOMA EXPERIMENTALLY INDUCED IN THE HAMSTER TONGUE
}

\author{
Kenji IzUmi ${ }^{1}$, Takeyasu Maeda ${ }^{2}$ and Tamio NaKaJima ${ }^{1}$ \\ ${ }^{1}$ First Department of Oral and Maxillofacial Surgery and ${ }^{2}$ Second Department of Oral Anatomy, School of Dentistry, Niigata Uni- \\ versity, Niigata 951, Japan
}

\begin{abstract}
Innervation to carcinomas induced by 9,10-dimethyl-1,2-benzanthracene (DMBA) in the hamster tongue was investigated by means of immunohistochemistry for calcitonin generelated peptide (CGRP). The application of DMBA induced papillomatous tumors with epithelial dysplasia and then well-differentiated squamous cell carcinomas showing cord-like invasion of the muscle layer developed under the papillomatous portion of the epithelium. The characteristic features of the innervation were the scarcity of CGRP-positive nerve fibers in the carcinomatous stroma and the loss of their relationships with blood vessels. In contrast, numerous fine CGRP-positive nerves which were associated with blood vessels and carcinoma nests were present in the carcinoma invading zone where infiltration of lymphocytes, neutrophils, mast cells and macrophages was recognized. In addition, a dense distribution of intensely immunopositive nerves was seen around arterioles in the invasion zone and in the surrounding muscle layer. The results indicate possible involvement of the CGRPpositive nerves in the dull pain associated with malignant tumors and cellular responses at the site of tumor invasion, and in providing sufficient blood supply to the tumor tissue which is devoid of autoregulatory mechanism of the blood flow.
\end{abstract}

Squamous cell carcinomas of the oral cavity produce a rapidly growing mass with ulceration. The rapid growth predisposes sufficient blood supply to the carcinomas. In fact, angiogenesis is promoted by a tumor angiogenesis factor that is produced and released by tumor cells in a variety of malignant tumors (24). Interestingly, however, the vasculature in malignant tumor tissue is insensitive to acetylcholine and catecholamines, indicating the absence of autoregulation of the blood flow (10, 32). In addition, oral carcinomas are usually not painful even in the presence of an ulcer in an early stage. All these findings may indicate an alteration in the innervation in tumor tissue.

Calcitonin gene-related peptide (CGRP), a neuropeptide consisting of 37 amino acids, has been identified in the analysis of calcitonin mRNA (2, 27). Immunohistochemical studies have demon- strated a wide distribution of CGRP in the central and peripheral nervous tissues $(11,27)$. The tongue also contains a considerable number of CGRP-positive nerve fibers (30). CGRP possesses multiple functions as a neurotransmitter, vasodilator and trophic effector and is believed to play some role even in tissue maintenance and renewal $(3,11,16$, 20). The role of CGRP in tumor tissue, however, has not been well elucidated. Thus, the present study was undertaken to clarify the response of nerve fibers to 9,10 -dimethyl-1,2-benzanthracene (DMBA)-induced carcinomas of the hamster tongue by means of immunohistochemistry for CGRP.

\section{MATERIALS AND METHODS}

\section{Carcinogenesis}

One hundred and twenty male golden hamsters, 7 
weeks of age and weighing 70-90 g, were used. The animals were divided into the control and two experimental groups. In one of the experimental groups, tongue carcinomas were induced by the method employed by Fujita et al. (7). A $0.5 \%$ solution of DMBA in acetone was applied to the left lateral border of the middle third of the tongue three times a week, but scratching the tongue with an endodontic barbed broach before the application of DMBA was spared. The procedure was discontinued at the 24 th week or later when a carcinomatous tumor was recognized macroscopically. In the other experimental group, the animals received application of acetone alone to the same region. No treatment was done in the animals of the control group. The animals were sacrificed at week intervals during 32 weeks of the experiment for histological and immunohistochemical study.

\section{Tissue Preparation}

After an intraperitoneal injection of sodium pentobarbiturate $(40 \mathrm{mg} / \mathrm{kg})$, the animals were perfused through the ascending aorta with Ringer's solution followed by $4 \%$ paraformaldehyde in $0.1 \mathrm{M}$ phosphate buffer, $\mathrm{pH} 7.4$, or Bouin's fluid. The tongues were removed and immersed in the same fixative overnight. The tissue specimens were then rinsed in $0.01 \mathrm{M}$ phosphate-buffered saline (PBS), $\mathrm{pH} 7.3$, containing $30 \%$ sucrose at $4{ }^{\circ} \mathrm{C}$ overnight. The specimens were rapidly frozen in liquid nitrogen and frozen sections were cut at $40-50 \mu \mathrm{m}$ in a cryostat (Sakura, Tokyo, Japan).

\section{Histology and Immunohistochemistry for CGRP}

Endogenous peroxidase was inactivated by treatment with $0.3 \% \mathrm{H}_{2} \mathrm{O}_{2}$ in absolute methanol for 10 min. A solution of PBS containing $0.3 \%$ Triton $\mathrm{X}-100$ was used to dilute antiserum and to rinse the sections. Floating sections were processed for immunohistochemistry for CGRP using polyclonal antibody raised in rabbit against synthetic rat CGRP (CA-08-220, Cambridge Research Biochemicals, Cambridge, U.K.). The primary antibody was diluted to 1:3,000 in PBS containing 0.3\% Triton $X-100$. The antigen-antibody reaction was visualized by the avidin-biotin-peroxidase method, using a commercially available kit (Histofine kit, Nichirei, Tokyo, Japan). The sections were incubated with the primary antibody for $18 \mathrm{~h}$ at room temperature, and then with goat biotinylated anti-rabbit
IgG. Peroxidase-labeled streptoavidin was used as the third layer. An enzyme reaction was developed with a mixture of $0.02 \%$ diaminobenzidine and $0.01 \% \mathrm{H}_{2} \mathrm{O}_{2}$ in $0.05 \mathrm{M}$ Tris buffer, $\mathrm{pH}$ 7.6. Some of the immunostained sections were counterstained with hematoxylin.

To examine the specificity of the CGRP immunostainings, sections were incubated either with the anti-CGRP antiserum that had been preabsorbed with the corresponding antigen $(10 \mu \mathrm{g} / \mathrm{ml}$ of diluted serum) for $24 \mathrm{~h}$ at $4^{\circ} \mathrm{C}$ or PBS containing $0.3 \%$ Triton $X-100$. The antigen-absorbed antiserum and PBS containing $0.3 \%$ Triton X-100 did not immunostain any neural elements.

Some of the frozen sections were stained with hematoxylin and eosin for histological observation. For identification of mast cells, serial frozen sections were stained with toluidine blue.

\section{RESULTS}

\section{Control Group}

Normal structure of the hamster tongue The mucosa of the hamster tongue was characterized by highly keratinized stratified squamous epithelium with filiform papillae on the dorsal surface. The mucosa on the ventral surface was devoid of filiform papillae (Fig. 1a).

Under the epithelium was a thin layer of the lamina propria and submucosal layer which contained many capillaries and venules dorsally, but ventrally much less blood vessels. The tongue itself was made up of interlacing bundles of striated muscle running in different planes. The interstitial connective tissue between muscle bundles also contained many arteries, veins and nerve bundles of varying sizes (Fig. 1a).

Distribution of CGRP-immunopositive nerve fibers There were many nerve fibers which showed CGRP-immunoreactivity with a beaded appearance in the hamster tongue. CGRP-positive nerve fibers coming from the muscle layer were distributed in the connective tissue papillae of the lamina propria through the submucosal layer. Most of them terminated in the vicinity of the epithelial layer (Fig. 1b), but there were some which penetrated into the epithelium. These nerve fibers had terminals with no specialized structure. There were no nerve fibers which were associated with capillaries.

CGRP-positive nerve bundles of varying sizes were also seen passing through the connective tis- 


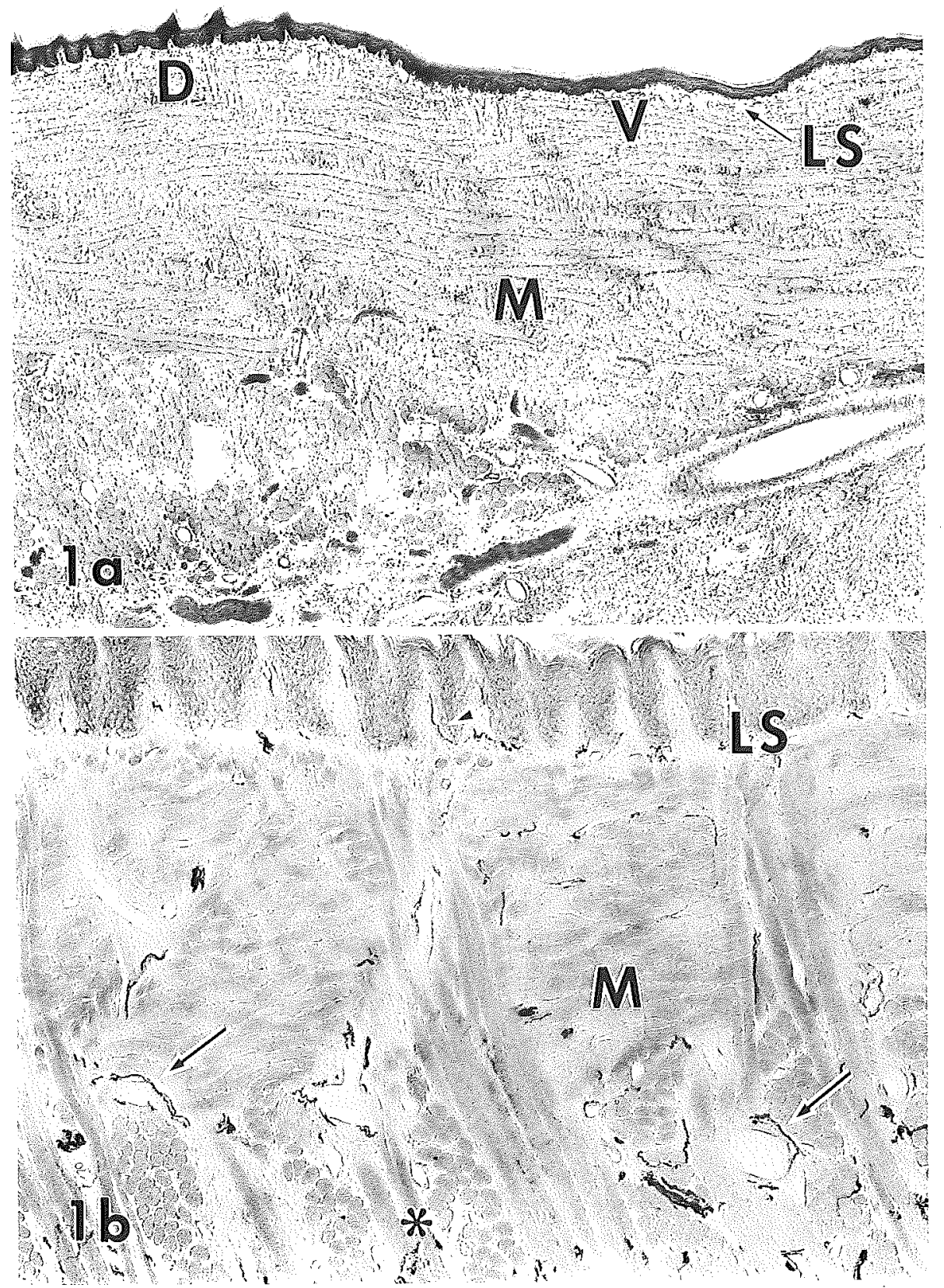

Fig. 1 a: Photomicrograph of lateral border of hamster tongue showing keratinized epithelium, thin lamina propria and submucosal layer (LS) and thick muscle layer (M). D, dorsal surface; V, ventral surface. Hematoxylin-and-eosin staining. $\times 40$. b: Photomicrograph showing distribution of CGRP-immunoreactive nerve fibers in tongue. Note close association of CGRP-immunopositive nerve fibers with blood vessels (arrows) and their extension in epithelial layer (arrowhead). Motor endoplates (*) are also seen in muscle layer (M). LS, lamina propria and submucosal layer. Immunostaining for CGRP. $\times 75$ 
sue in the muscle layer. Some of them were associated with blood vessels with smooth muscle and formed networks around them (Fig. 1b). Most of the CGRP-positive nerves terminated in the striated muscle to form motor endoplates (Fig. 1b). Only a small proportion of CGRP-positive fibers passed through the muscle layer towards the lamina propria via the submucosal layer.

\section{Experimental Group with Application of DMBA}

The experimental period was classified into the initial stage (1-4 weeks), epithelial dysplasia stage (514 weeks), papillomatous stage (15-23 weeks) and carcinoma stage (24-32 weeks) by histological evaluation.

The initial stage Both grossly and histologically, no significant changes were observed at the site of DMBA application except for slight hyperplasia of the epithelial cell layer and thickening of the submucosal layer.

Distribution and terminal formation of CGRPpositive nerves were not substantially different from those in the control group.

The epithelial dysplasia stage The mucosa in the treated region become gradually thick and rough at about 5 weeks.

Histologically, the mucosal epithelium showed thickening of the prickle cell layer and elongation of irregularly shaped rete ridges. There was hyperkeratosis with the presence of keratohyaline granules. Crowding of basal cells accompanied by basaloid changes of parabasal cells was also recognized. The submucosal layer which had become widened with a fibrous matrix contained many small blood vessels, but no conspicuous changes were seen in the lamina propria (Fig. 2a). Cell infiltration mainly consisting of lymphocytes and neutrophils was seen in the submucosal layer. No particular changes were observed in the muscle layer.

There was an increase of the CGRP-positive nerves distributed just beneath the epithelial layer as well as those entering the epithelial cell layer (Fig. 2b). CGRP-positive nerves in the submucosal layer showed a tendency to gather around small blood vessels and were thickly immunostained in portions (Fig. 2b).

The papillomatous stage Glossly, slightly raised lesions with a rough surface developed at the treatment site became nodular and papillomatous in this stage.

On histological examination, the lesions showed a papillomatous growth of the mucosal epithelium with dysplastic epithelium in the surrounding area. Cellular atypism and keratinization of epithelial cells of the papillomatous lesions became more evident and mitotic figures were occasionally observed. The fibrous tissue core of the papillomas and underlying submucosal layer contained many blood vessels (Fig. 3a).

Although epithelial projections or islands showing cellular atypism were observed in the submucosal layer late in this stage, downgrowth of the epithelial cells into the muscle layer was not recognized. Later in this stage, a few ulcerations were observed in the papillomatous lesion. Neutrophils and lymphocytes were the main constituents of cell infiltration and mast cells were rarely encountered in the fibrous tissue core of papillomas and in the underlying submucosal layer.

The characteristic feature of immunostained specimens was the scarcity of CGRP-positive nerves in the fibrous tissue core of papillomas. Only a few CGRP-positive nerves were present in association with small blood vessels (Fig. 3b). Numerous CGRP-positive nerves, however, were distributed around small blood vessels in the submucosal layer at the base of the papillomatous lesion and some of them were thickly immunostained (Fig. $3 c)$. In this area, CGRP-positive nerves were also observed in close proximity of the epithelium. There was no significant change in the distribution of CGRP-positive nerves in the muscle layer.

The carcinoma stage The papillomatous lesions further increased in size and developed into carcinomatous tumors with ulcerations having a yellow necrotic surface.

Histologically, development of squamous cell carcinoma was recognized under the papillomatous portion of the epithelium. Although there was a wide variation from well-differentiated carcinoma with an evident tendency to keratinization and formation of cancer pearls to poorly-differentiated carcinoma showing relatively little keratinization, the majority of the carcinomas was of relatively welldifferentiated type with cord-like invasion of the underlying fibrous tissue and muscle layer (Fig. 4a). Carcinoma cells showed varying degrees of cellular atypism, hyperchromatism and increased nucleocytoplasmic ratio. Mitotic figures were also seen. In the carcinomatous stroma of the invasion zone, capillaries, venules and arterioles with smooth muscle were seen in abundance (Fig. 4b), and there was a moderate degree of lymphocytic 


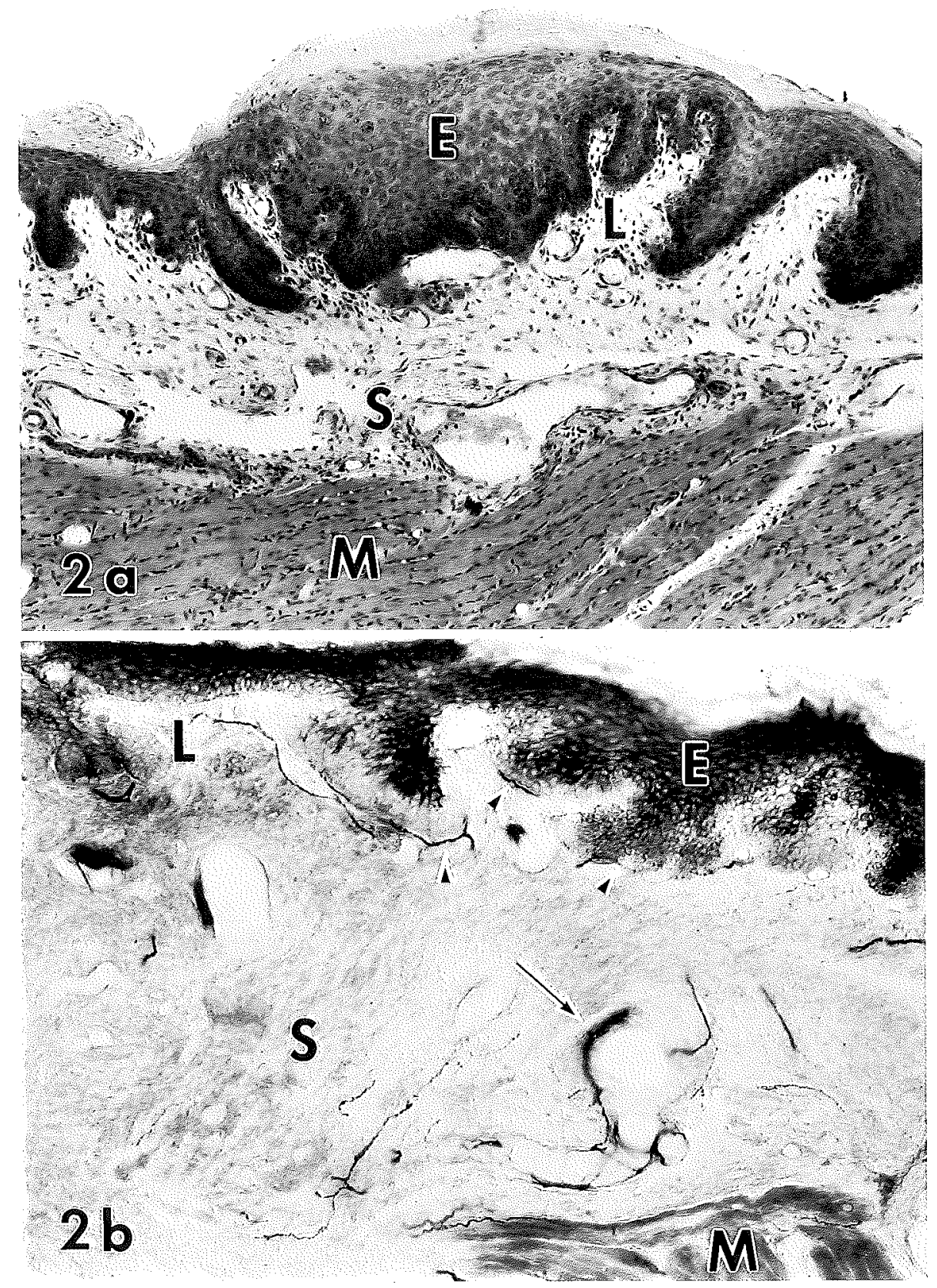

Fig. 2 a: Photomicrograph showing dysplastic changes of epithelial layer (E) and thickening of submucosal layer (S). L, lamina propria; M, muscle layer. Hematoxylin-and-eosin staining. $\times 100 . \mathrm{b}$ : Photomicrograph showing distribution of CGRPimmunopositive fibers beneath epithelial layer (E, arrowheads) and around blood vessels (arrow) in submucosal layer (S). L, lamina propria; M, muscle layer. Immunostaining for CGRP. $\times 100$

and neutrophilic infiltration and many mast cells and macrophages were also seen (Fig. 4c).

Blood vessels of varying sizes were observed in the carcinomatous stroma and in the fibrous core within the papillomatous tumor. Inflammatory cell infiltration was limited to the fibrous tissue under the ulcerations.

CGRP-positive nerve fibers observed in the fibrous core of the papillomatous portion were very scarce and the same finding was obtained in the 

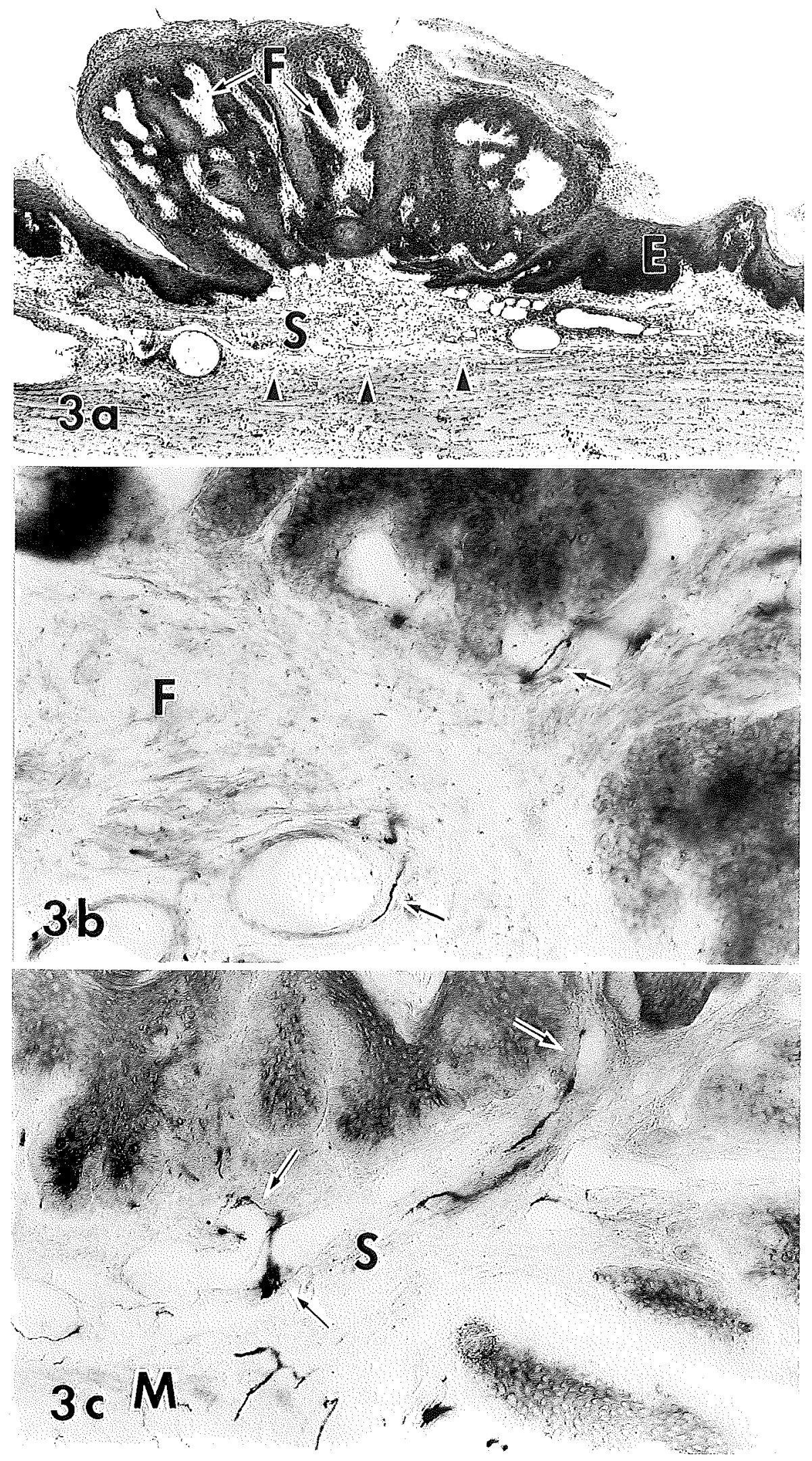

Fig. 3 a: Photomicrograph showing papillomatous growth of dysplastic epithelium (E) with narrow fibrous tissue core (F). There is no evidence of epithelial downgrowth into muscle layer (arrowheads). Many blood vessels are seen in fibrous tissue and submucosal layer. S, submucosal layer. Hematoxylin-and-eosin staining $\times 50$. b: Photomicrograph showing scarcity of CGRPimmunopositive nerve fibers around blood vessels (arrows) in fibrous tissue core (F) of papillomatous growth. Immunostaining for CGRP. $\times 150 . \mathrm{c}$ : Photomicrograph showing many CGRP-positive nerves distributed around blood vessels (arrows) at base of papillomatous growth. $\mathrm{M}$, muscle layer; S, submucosal layer. Immunostaining for CGRP. $\times 100$ 


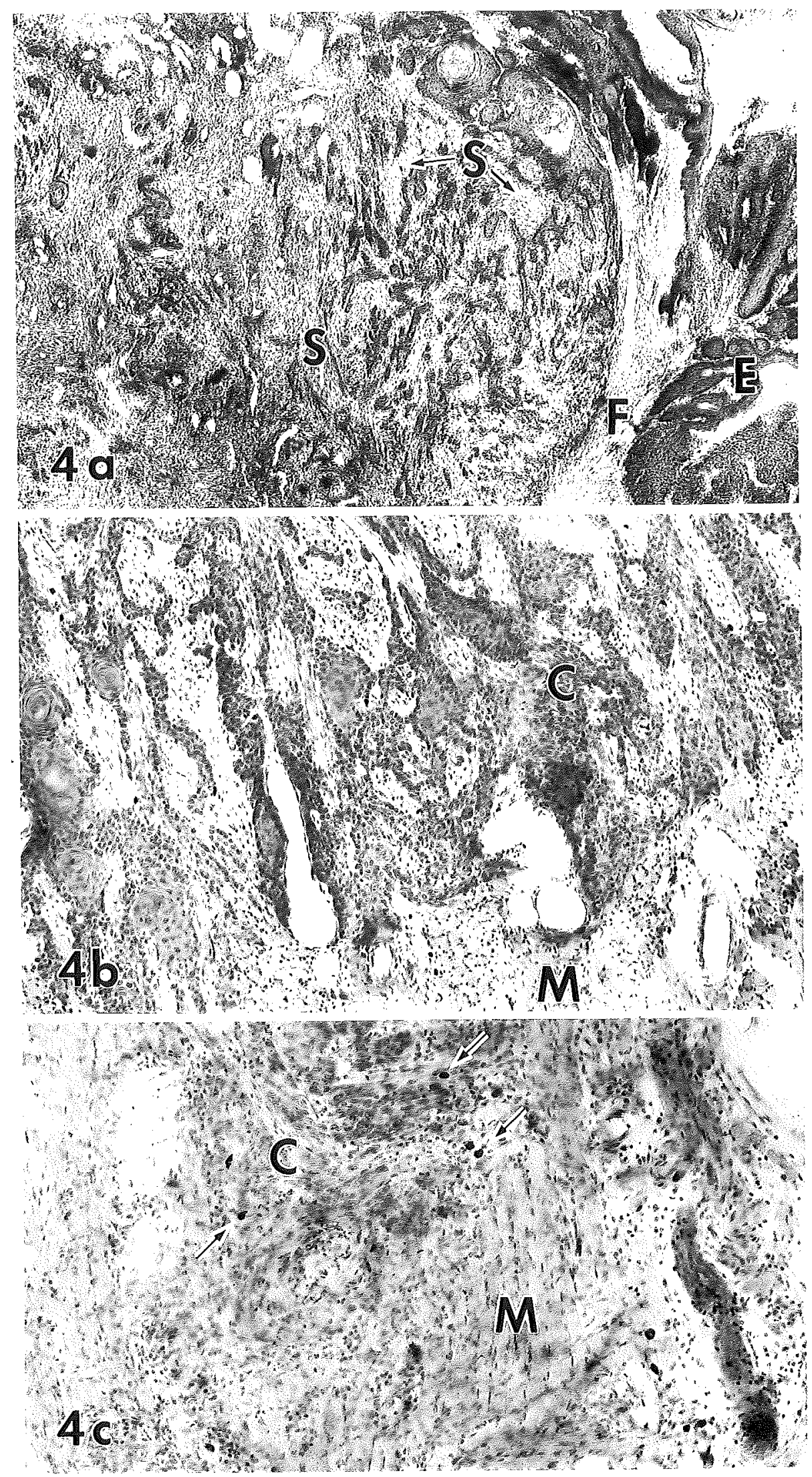

Fig. 4 a: Photomicrograph showing papillary growth of dysplastic epithelium (E) and underlying squamous cell carcinoma. Many blood vessels are seen in carcinomatous stroma (S) and surrounding fibrous core (F). Hematoxylin-andeosin staining. $\times 40$. b: Photomicrograph of carcinoma invading zone showing invasion of muscle layer (M). Blood vessels are also seen in abundance. C, carcinoma nests. Hematoxylin-and-eosin staining. $\times 100$. c: Photomicrograph showing presence of mast cells (arrows) in invasion zone. C, carcinoma cells; $\mathrm{M}$, muscle layer. Hematoxylin-and-eosin staining. $\times 150$ 


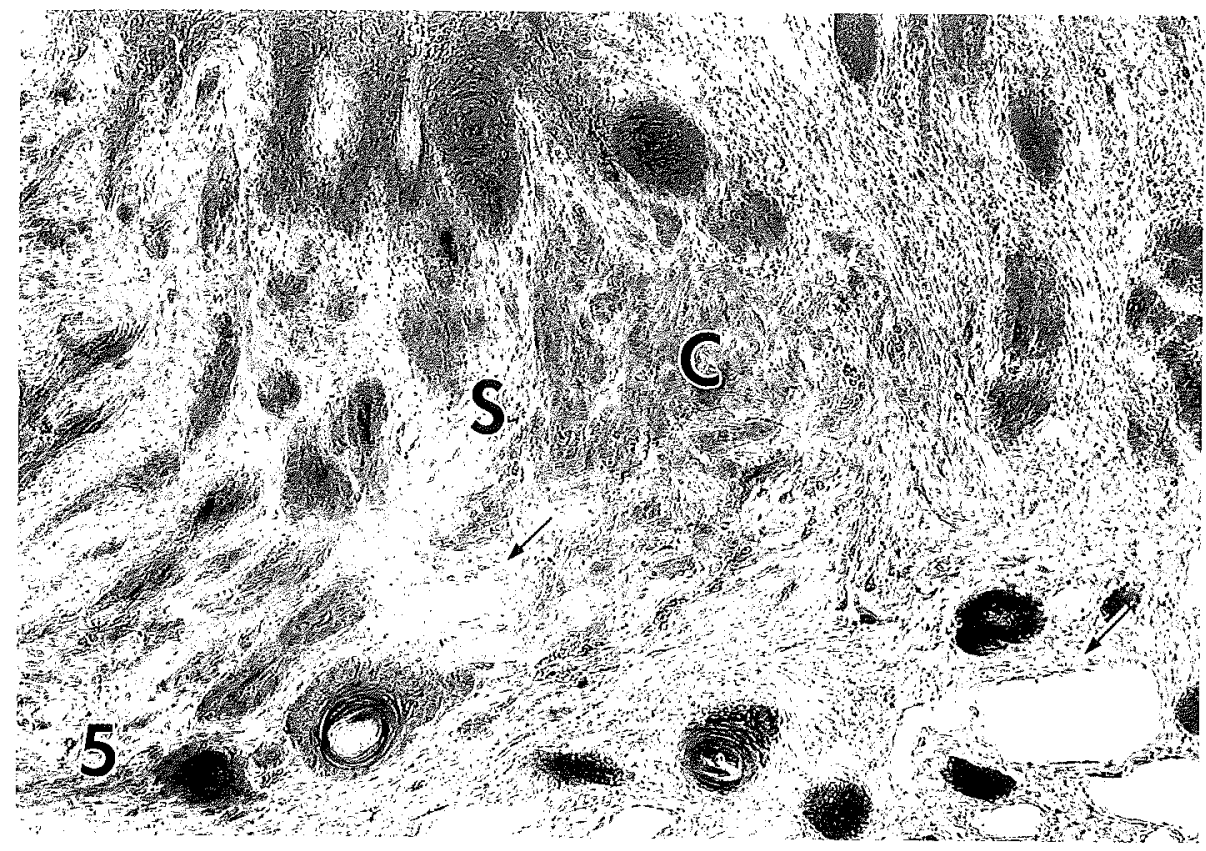

Fig. 5 Photomicrograph showing scarcity of CGRP-positive nerves in carcinomatous stroma beneath papillomatous portion. Note absence of CGRP-positive nerves (arrows) around blood vessels. $\mathrm{C}$, carcinoma nests; $\mathrm{S}$, carcinomatous stroma. Immunostaining for CGRP counterstained with hematoxylin. $\times 100$

carcinomatous stroma. Most of them terminated in the fibrous core and only a few of them penetrated into the carcinoma nests (Fig. 5). There were no immunoreactive nerve fibers which were associated with blood vessels (Fig. 5).

On the other hand, numerous fine CGRP-immunopositive nerve fibers were observed in the carcinoma invading zone (Fig. 6a). Some of them were located close to carcinoma nests and appeared to be in direct contact with carcinoma cells (Fig. 6b). Many fine CGRP-immunopositive nerve fibers were also seen twining around small blood vessels in this region (Fig. 6c). In addition, a dense distribution of CGRP-positive nerves with thick immunoreactivity was observed around arterioles with smooth muscle both in the invasion zone and in the surrounding intact muscle layer (Fig. 7, a and b). The distribution of CGRP-positive nerves in the latter region was denser than in the control tongue (compare Figs. 1b and 7a). The histological changes and the response of CGRP-immunopositive nerves at this stage are schematically shown in Fig. 8.

Throughout the experiment, tumor cells of both papillomas and carcinomas and epithelial cells in the parabasal and prickle cell layers of the normal and dysplastic mucosa seemed to be positively immunostained. But the staining did not disappear completely after the absorption test.

\section{Experimental Group with Application of Acetone}

The site of experiment remained flat and an exophytic tumor developed in none of the animals. The submucosal layer became slightly widened, but no other changes were observed in the histological and immunohistochemical findings.

\section{DISCUSSION}

The present immunohistochemical study demonstrated an alteration in the distribution of CGRP. positive nerves in and at the periphery of DMBAinduced carcinomas of the hamster tongue. In this study, squamous cell carcinomas were induced by the method introduced by Fujita et al. (7). In their original procedure, the lateral border of the tongue was scratched with an endodontic barbed broach before applying DMBA in acetone to reduce the period for inducing the carcinomas. It is conceiv- 


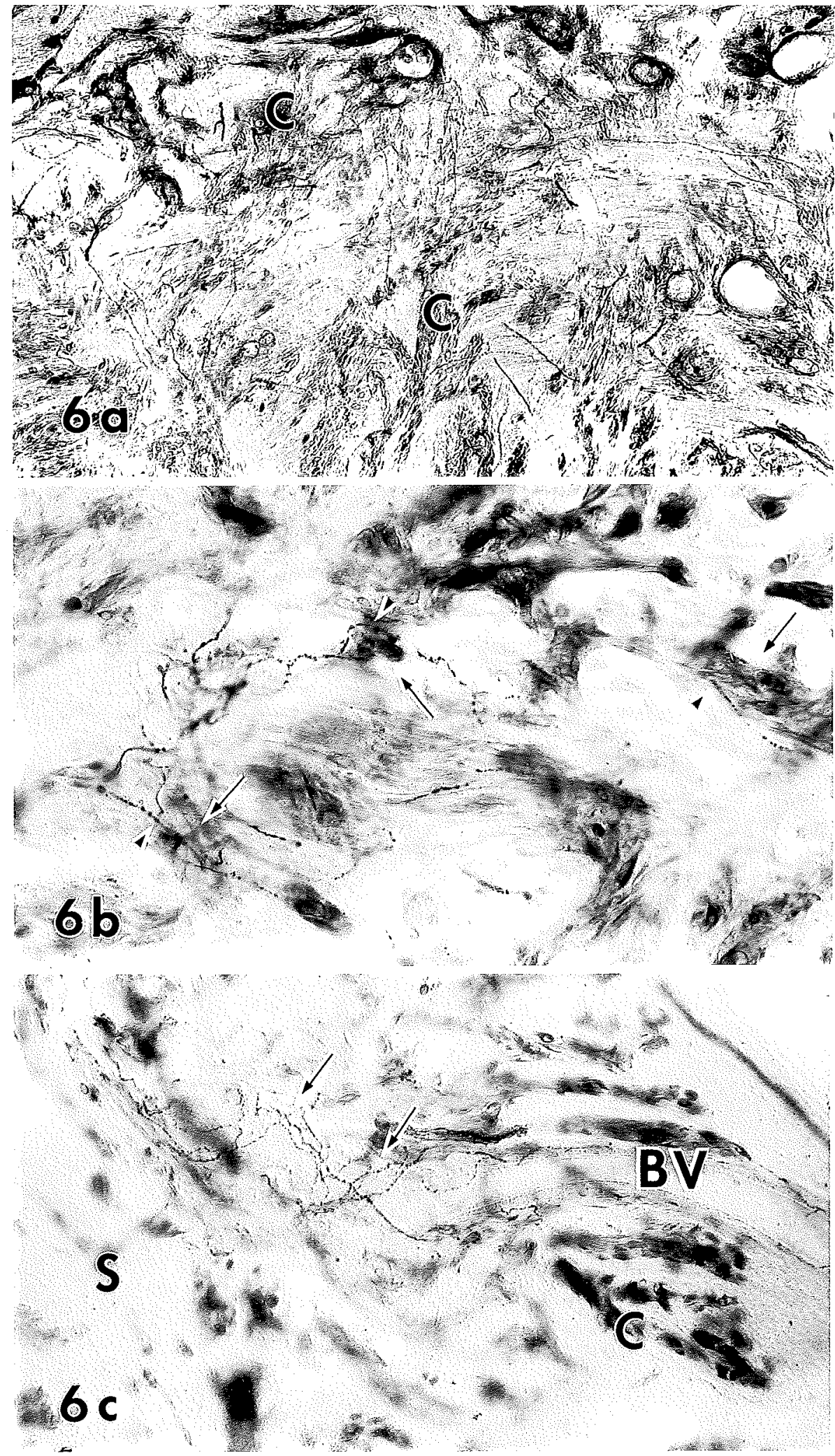

Fig. 6 a: Photomicrograph showing presence of numerous fine CGRP-positive nerve fibers in carcinoma invading zone. C, carcinoma nests. Immunostaining for CGRP. $\times 80$. b: Photomicrograph showing close relationship of CGRP-positive nerve fibers (arrowheads) with carcinoma cells (arrows) in invasion zone. Immunostaining for CGRP. $\times 200$. c: Photomicrograph showing CGRP-positive nerve fibers (arrows) twining around small blood vessels (BV) in invasion zone. $C$, carcinoma cells; S, carcinomatous stroma. Immunostaining for CGRP. $\times 120$ 


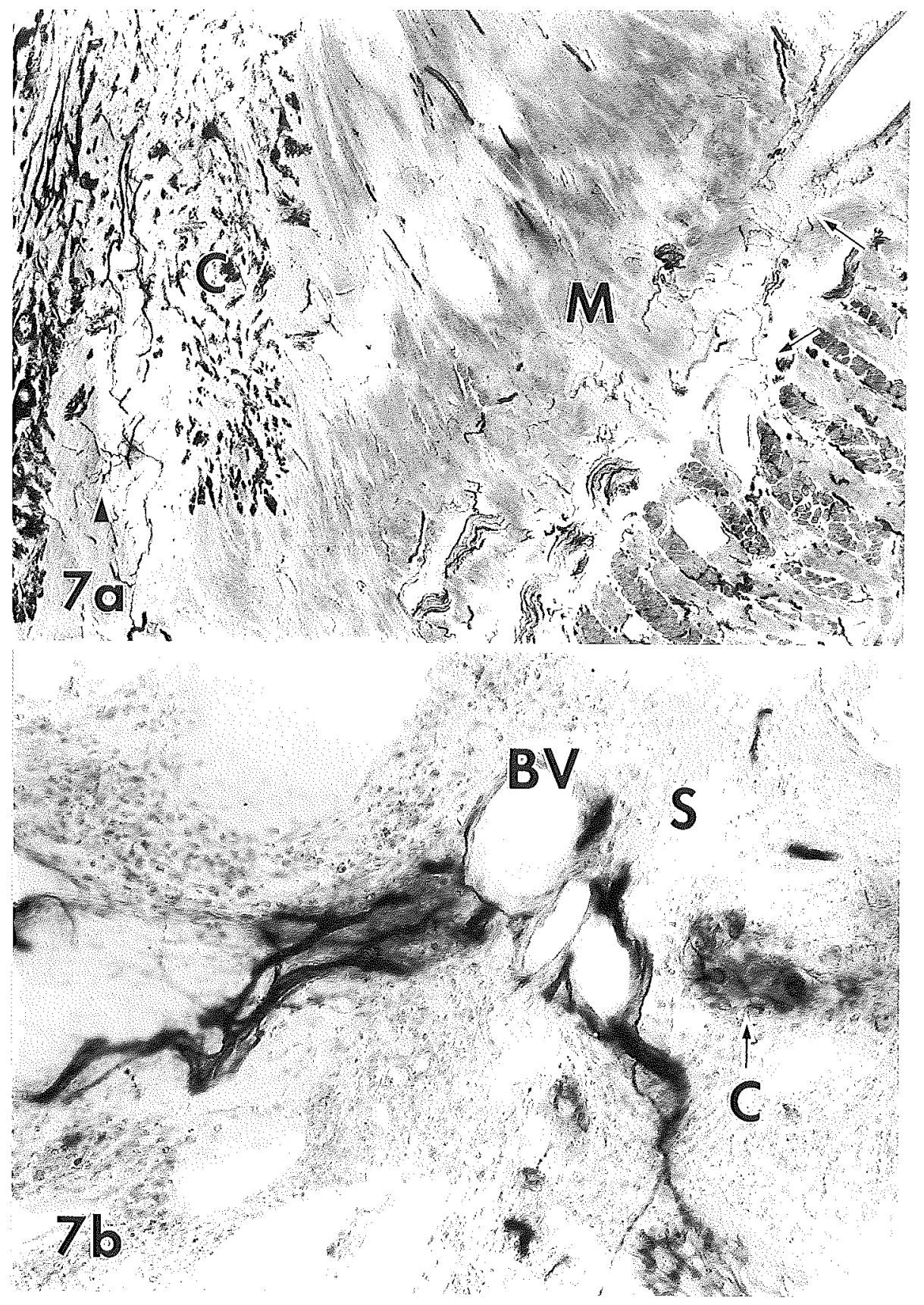

Fig. 7 a: Photomicrograph showing dense distribution of CGRP-positive nerve fibers around blood vessels in carcinoma invading zone (arrowhead) and surrounding muscle layer (arrows). C, carcinoma nests; $\mathrm{M}$, muscle layer. Immunostaining for CGRP, $\times 30$. b: Photomicrograph showing CGRP-positive nerves with thick immunoreactivity distributed around blood vessels in carcinomatous stroma $(\mathrm{S})$ of invasion zone. BV, blood vessels; C, carcinoma cells. Immunostaining for CGRP. $\times 200$

able, however, that the procedure itself causes direct damage and subsequent inflammation which would lead to formation of granulomas and modify the response of nerve fibers to the development of carcinomas (9). Indeed, our preliminary experiments showed that intense inflammation was 


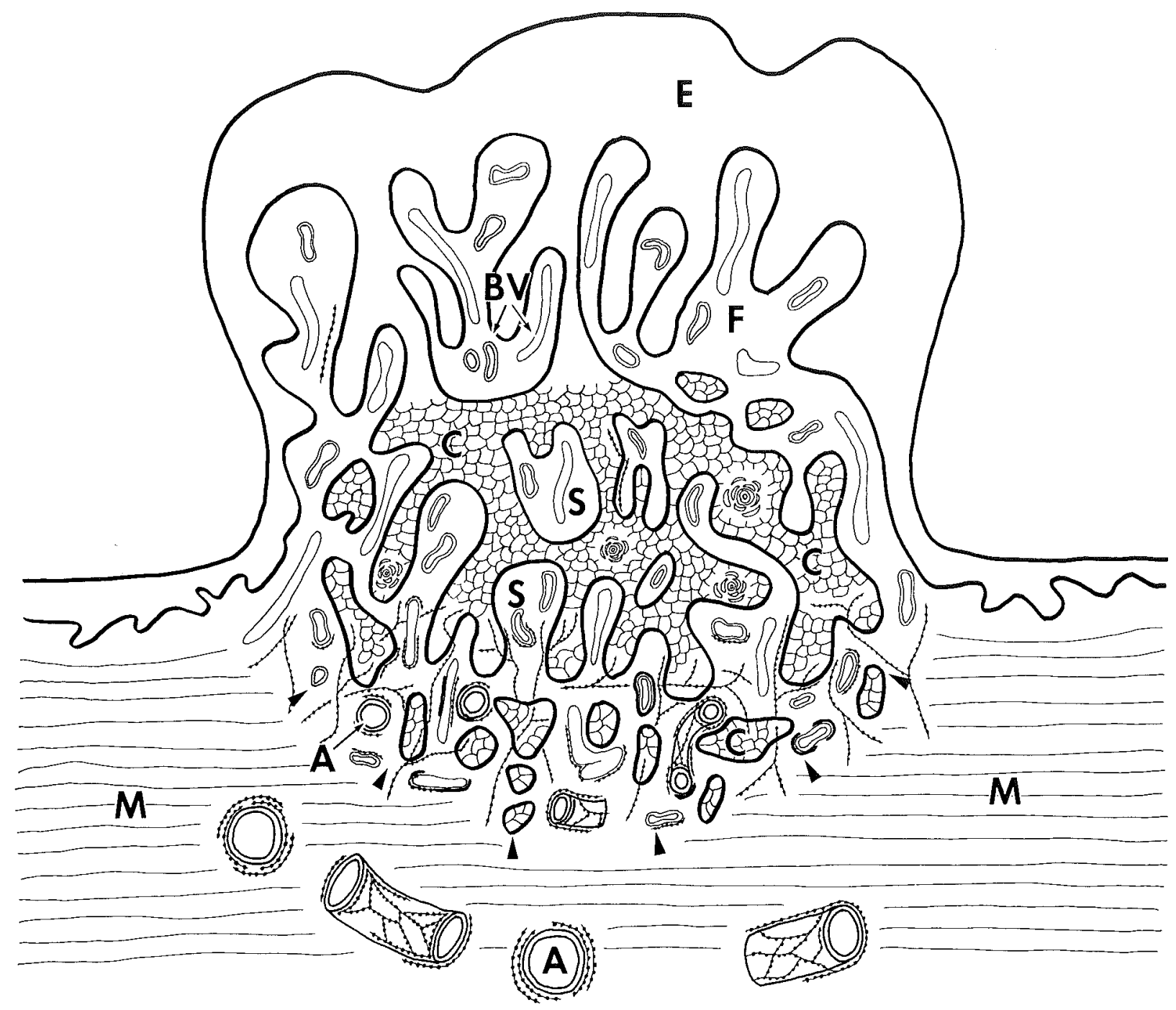

Fig. 8 Schematic diagram showing histological changes and distribution of CGRP-positive nerves (shown in red) in carcinoma stage. Arrowheads indicate front of carcinoma invading zone. A, artery or arteriole; BV, small blood vessel; C, carcinoma nests; E, papillomatous epithelium; F, fibrous core; M, muscle layer; S, carcinomatous stroma

induced in the tumor and surrounding tissues by the scratching. Therefore, the procedure was spared in this experiment and the effect of acetone, the solvent of DMBA, was studied. Obviously, the carcinogenesis was responsible for the alteration of innervation because there were no significant changes in the distribution of CGRP-nerve fibers between the acetone and control groups.

The innervation of tumor tissue has been studied by many researchers. In a study of gastric cancer using silver impregnation method, Fukuoka indicated that nerve fibers would undergo degeneration and disappear from the tumor tissue (8).
Futamura also stated that there was an evident degenerative tendency of nerve fibers with invasion of chemically induced carcinomas (9). According to Oyama (22), however, although nerve fibers might undergo various changes, apparently normal nerve fibers existed in malignant tumors and some of them were considered to be regenerated nerve fibers. The author, therefore, indicated the necessity of innervation for the growth of tumors (22). Sekiya also observed that nerve fibers of the tongue entered the cancer tissue without showing any degenerative change (28). In the present study, the presence of CGRP-positive nerve fibers was dem- 
onstrated in the stroma of the DMBA-induced carcinomas, but they were much less in number than those in the control normal tissue except in the stroma of carcinoma invading zone where numerous CGRP-positive nerve fibers were demonstrated. The inconsistent findings reported by the previous authors might be due to the difference of nerve distribution in the tumor tissue by site.

Immunostaining for CGRP is a useful technique for identifying sensory neurons, because CGRP functions as a neurotransmitter of primary sensory neurons, and is contained predominantly in thin nerve fibers such as thinly myelinated $\mathrm{A}_{\delta}$ fibers and unmyelinated $\mathrm{C}$ fibers $(11,16,17)$. In addition to nerve fibers, tumor cells and epithelial cells of the mucosa seemed to be immunostained, but the staining was not specific for CGRP because it did not disappear completely after the absorption test. Although the number of CGRP-positive nerves in the submucosal layer was increased at the epithelial dysplasia stage, the scarcity of their innervation in the fibrous core of the papillomatous portion as well as in the carcinomatous stroma was the characteristic feature of the CGRP-positive nerve innervation. An analogous finding was obtained with immunostaining for neurofilament protein in our study (unpublished observation). The results may indicate that the pain threshold of the malignant tumor tissue is higher than that of the normal tissue.

In contrast, numerous fine nerve fibers showing CGRP-immunoreactivity were concentrated and uniformly distributed in the invasion zone. The distribution and appearance of CGRP-positive nerves in this region were different from those in the intact muscle layer. Obviously, these fibers are regenerated in response to stimuli resulting from tumor invasion. Närhi indicated possible participation of $\mathrm{C}$ fibers in the induction of dull pain in chronic pulpitis (19) because an increase of fine CGRP-positive nerves at the site of mild inflammation in the dental pulp has been reported by Kimberly and Byers (13) and $\mathrm{C}$ fibers respond to various stimuli caused by thermal, mechanical and chemical irritants (19). It is not unlikely, therefore, that the CGRP-positive nerves in the invasion zone are involved in chronic dull pain associated with malignant tumors. The interpretation is consistent with the clinical findings that most of oral carcinomas are initially painless, or, if any, cause only mild dull pain.
Another role of the dense innervation of CGRPpositive fibers in the invasion zone would be to facilitate tissue reactions either against or for carcinoma invasion because CGRP is known to have multiple biological functions. There was an infiltration of lymphocytes and neutrophils in the invasion zone. In addition, mast cells and macrophages were seen in abundance in the invasion zone. According to Kjartansson et al. (15) and Kjartansson and Dalsgaard (14), wound healing of experimental critical flaps was impaired by pretreatment with capsaicin, an agent to deplete CGRP from primary sensory neurons, whereas intravenous injections of CGRP in doses much lower than those required for vasodilation increased significantly the survival rate of the flaps. CGRP is capable of activating macrophage and leukocyte functions, proliferating fibroblasts and smooth muscle cells (1, $18,23)$ and enhancing the effects of neuropeptide such as substance $P(20,21)$. CGRP and substance $P$ release histamine from mast cells $(6,21,25)$. Mast cells are known to participate in tissue remodeling by dissolving connective tissue matrix, promoting fibroblast proliferation and enhancing tumor angiogenesis $(4,5,12,26)$. Thus, CGRP may be involved in cellular responses at the site of carcinoma invasion.

It is noteworthy that some of these CGRP-positive nerves were frequently located in close proximity to carcinoma nests, or seemed to be in contact with carinoma cells. The findings may indicate the presence of functional relationships between the CGRP-positive nerves and carcinoma cells, but it remains to be further clarified.

The most notable findings were the difference in the density of CGRP-positive nerves located in close association with blood vessels between the carcinomatous stroma and the carcinoma invading zone and surrounding muscle layer. Arterioles in the latter tissues were densely innervated by numerous CGRP-immunopositive nerves and formed networks, whereas no CGRP-positive nerves were observed around blood vessels in the carcinomatous stroma. It has been shown that tumor vessels do not respond to the injection of angiotensin II (29). The absence of autoregulatory mechanism of the blood flow in the tumor tissue may indicate that blood supply to the tumor depends on the blood flow of arteries in the tissue surrounding the tumor. Since CGRP is a potent local vasodilator whose duration time is long $(31,33)$, the blood flow in the tumor tissue may be controled by 
the CGRP-innervated arteries. Therefore, the dense network of CGRP-positive nerves around the arterioles in the tissues surrounding the carcinoma may provide a neurologically advantageous condition for the growth of the tumor.

The authors thank Professors T. Saku and Y. Takano for their valuable comments and suggestions. The author's thanks are due to Emeritus Professor S. Kobayashi and Dr O. Sato for their encouragements, and Messrs K. Takeuchi and M. Hoshino for their technical assistance. This study was partly supported by a grant-in-aid for Scientific Research (No. 03670845) from the Ministry of Education, Science and Culture, Japan.

Received 19 September 1991; and accepted 30 September 1991

\section{REFERENCES}

1. Abello J., Kaiserlian-Nicolas D., Cuber J. C., RevilLARD J. P. and Chayvialle J. A. (1990) Identification of high affinity calcitonin gene-related peptide receptors on a murine macrophage-like cell line. Ann. N.Y. Acad. Sci. 594, 364-366

2. Amara S. G., Jonas V., Rosenfeld M. G., Ong E. S. and EvaNs R. M. (1982) Alternative RNA processing in calcitonin gene expression generates mRNAs encoding different polypeptide products. Nature 298, 240-244

3. Brain S. D., Williams T. J., Tippins J. R, Morris H. R. and MacInTYRe I. (1985) Calcitonin gene-related peptide is a potent vasodilator. Nature 313, 54-56

4. Dabbous M. K., Woolley D. E., Haney L., Carter L. M. and Nicolson G. L. (1986) Host-mediated effectors of tumor invasion: role of mast cells in matrix degradation. Clin. Exp. Metastas. 4, 141-152

5. Folkman J. (1985) Tumor angiogenesis, Adv. Cancer Res. 43, 175-203

6. Foreman J. C. (1987) Neuropeptides and the pathogenesis of allergy. Allergy 42, 1-11

7. Fujita K., Kaku T., Sasaki M. and Onoe T. (1973) Experimental production of lingual carcinomas in hamsters by local application of 9,10-dimethyl-1,2-benzanthracene. $J$. Dent. Res. 52, 327-332

8. FuKuoKA Y. (1959) Neural distribution in the cancer tissues of the human stomach. II. On the neural distribution in the cancer tissues of the human stomach. J. Nara Med. Associ. 10, 433-447 (in Japanese with English abstract)

9. Futamura H. (1988) Changes of the nervous tissue in the experimental hamster lingual tumor. J. Kyushu Dent. Soci. 42, 705-732 (in Japanese with English abstract)

10. Hafström L., Nobin A., Persson B. and Sundquist K. (1980) Effects of catecholamines on cardiovascular response and blood flow distribution to normal tissue and liver tumors in rats. Cancer Res. 40, 481-485

11. Ishida-Yamamoto A. and Tohyama M. (1989) Calcitonin gene-related peptide in the nervous tissue. Prog. Neurobiol. 33, 335-386

12. Kessler D. A., Langer R. S., Pless N. A. and Folkman J. (1976) Mast cells and tumor angiogenesis. Int. J. Cancer 18, 703-709
13. Kimberly C. L. and Byers M. R. (1988) Inflammation of rat molar pulp and periodontium causes increased calcitonin gene-related peptide and axonal sprouting. Anat. Rec. 222, 289-300

14. Kuartansson J. and Dalsgaard C.-J. (1987) Calcitonin gene-related peptide increases survival of a musculocutaneous critical flap in the rat. Eur. J. Pharmacol. 142, 355358

15. Kuartanssion J., Dalsgaard C.-J. and Jonsson C.-E. (1987) Decreased survival of experimental critical flaps in rats after sensory denervation with capsaicin. Plast. Reconstr: Surg. 79, 218-221

16. Kruger L., Silverman J. D., Mantyh P. W., Sternini C. and Brecha N. C. (1989) Peripheral patterns of calcitoningene-related peptide general somatic sensory innervation: cutaneous and deep terminations. J. Comp. Neurol. 280, 291-302

17. Kuraishi Y., Nanayama T., Ohno H., Minami M. and SATOH M. (1988) Antinociception induced in rats by intrathecal administration of antiserum against calcitonin generelated peptide. Neurosci. Lett. 92, 325-329

18. Mitsuhashi M. and Payan D. G. (1987) The mitogenic effects of vasoactive neuropeptides on cultured smooth muscle cell lines. Life Sci. 40, 853-861

19. VÄrhi M. V. O. (1990) Intradental sensory units. In Dynamic Aspects of Dental Pulp: Molecular Biology, Pharmacology and Pathophysiology (ed. INoKI R., Kudo T. and OLGART L. M.) Chapman and Hall, London, pp. 137-149

20. Oku R., Satoh M., Fuji N., Otaka A., Yajima H. and TAKAG1 H. (1987) Calcitonin gene-related peptide promotes mechanical nociception by potentiating release of substance P from the spinal dorsal horn in rats. Brain Res. 403, 350-354

21. OlgaRt L. M. (1990) Functions of peptidergic nerves. In Dynamic Aspects of Dental Pulp: Molecular Biology, Pharmacology and Pathophysiology (ed. INOKI R., KUDO T. and Olgart L. M.) Chapman and Hall, London, pp. 349-362

22. Oyama I. (1978) A neuropathological study in malignant tumor tissue. J. Kyushu Dent. Soci. 31, 554-573 (in Japanese with English abstract)

23. Payan D. G., McGillis J. P., Renold F. K., Mitsuhashi M. and Goetzl E. J. (1987) Neuropeptide modulation of leukocyte function. Ann. N. Y. Acad. Sci. 496, 182-191

24. Phillips P., Steward J. K. and Kumar S. (1976) Tumour angiogenesis factor (TAF) in human and animal tumours. Int. J. Cancer 17, 549-558

25. Piotrowski W. and Foreman J. C. (1986) Some effects of calcitonin gene-related peptide in human skin and on histamine release. Brit. J. Dermatol. 114, 37-46

26. Roche W. R. (1985) Mast cells and tumors: The specific enhancement of tumor proliferation in vitro. Amer. $J$. Pathol. 119, 57-64

27. Rosenfeld M. G., Mermod J.-J., Amara S. G., Swanson L. W., Sawchenco P. E., Rivier J., Vale W. W. and Evans R. M. (1983) Production of a novel neuropeptide encoded by the calcitonin gene via tissue-specific RNA processing. Nature 304, 129-135

28. SexiYa S. (1958) A neuropathological study of cancer grown in the tongue and the rectum. Arch. Jap. Chirur: 27, $880-892$

29. Suzuki M., Hori K., Abe I., Saito S. and Sato H. (1981) A new approach to cancer chemotherapy: Selective enhancement of tumor blood flow with angiotensin II. J. Nat. Cancer Inst. 67, 663-669 
30. Terenghi G., Polak J. M., Rodrigo J., Mulderry P. K. and Bloom S. R. (1986) Calcitonin gene-related peptideimmunoreactive nerves in the tongue, epiglottis and pharynx of the rat: Occurrence, distribution and origin. Brain Res. 365, 1-14

31. Uddman R., Edvinsson L., Ekblad E., Håkanson R. and SundLeR F. (1986) Calcitonin gene-related peptide (CGRP): perivascular distribution and vasodilatory effects.
Regul. Peptides 15, 1-23

32. Young S. W., Muller H. H. and MarinceK B. (1983) Response of neoplastic and normal vasculature to acetylcholine. Eur. J. Cancer Clin. Oncol. 19, 383-387

33. Zaidi M., Bevis P. J. R., Girgis S. I., Lynch C., Stevenson J. C. and MaCInTYLE I. (1985) Circulating CGRP comes from the perivascular nerves. Eur. J. Pharmacol. 117, 283284 